\title{
FIGURAS SUBVERSIVAS EN LOS TEXTOS DE LA ANTIGÜEDAD
}

\author{
SUBVERSIVE FIGURES IN TEXT IN THE ANTIQUITY
}

Mabel Haro Peralta

Universidad de Aguas Calientes, México

\section{Resumen:}

La Edad Antigua abarca el período histórico desde la invención de la escritura hasta la caída del Imperio Romano. Este artículo nos ofrece un estudio profundo sobre los roles de la mujer en la Edad Antigüedad a través de textos clásicos de la épica griega. Desde una perspectiva de género, nos centraremos en aquellas mujeres que no actuaron de acuerdo al orden sociocultural ni los estereotipos sociales de la época.

\section{Palabras Claves:}

Edad Antigua, mujer, figuras femeninas.

\section{Abstract:}

Ancient Age covers the historical period from the origin of the writing to the fall of Roman Empire. This article offers us a Deep study on the female roles in the Ancient Age throughout the classical texts of Greek epic. From a gender perspective, we will focus on those women who did not act according the socio-cultural system and the social stereotypes of that time.

\section{KEY WORD:}

Ancient Age, woman, female figures. 
La presencia de la mujer en la Edad Antigua ${ }^{1}$ es cada vez más extendida en los ámbitos de investigación. Abundantes y documentados estudios han analizado su significación, función y desarrollo en las sociedades, puestas en relieve a través de la literatura. Al acercarnos a éste periodo, encontramos un cúmulo informativo conformado por textos mitológicos, épicos o sagrados, separados por imperceptibles líneas que les describen a unos y otros. (GUAL, 12:1987) La mayoría están escritos por hombres toda vez que la "autoridad" sobre la escritura recaía sobre ellos. De modo que, resulta obvio pensar en las figuras femeninas contenidas en los escritos antiguos, únicamente como idealizaciones o simbolizaciones de las mujeres elaborada desde una subjetividad masculina.

Nuestro análisis se acerca en un primer momento a la perspectiva de género, revisando la vida de las mujeres en la Edad Antigua. De manera sociológica nos conduciremos por las diversas circunstancias sociales, económicas, políticas y religiosas que condujeron a los antiguos sistemas sociales al sometimiento del género femenino. En un segundo momento, a diferencia de la descripción de corte sociológica anteriormente elaborada, mencionaremos taxonómica y simbólicamente a aquéllas figuras femeninas que subvirtieron el orden social para una mujer en la Edad Antigua y que están contenidas en las narraciones de La Iliada y La Odisea (siglo VIII u VII a. C) de Homero y La Teogonía (siglo VII u VIII a. C.) de Hesiodo.

\section{LAS MUJERES EN EL PERíodo ANTIGUO}

El periodo histórico denominado como Edad Antigua abarca desde la invención de la escritura ("comienzo de la historia") hasta la caída del Imperio Romano de occidente en el 459 d. C. La mayoría de las mujeres en la Edad Antigua, trabajaban la tierra, ellas recibían una paga menor a la de los hombres, aunque realizaran los mismos trabajos. En las ciudades, vendían alimentos, ropas, ofrecían alojamiento y comida, dirigían

1 Los primeros estudios sobre las mujeres en la Edad Antigua datan de 1800, la realizan autores como J.J. Bachofen, Das Mutterrecht. Eine Untershung über dic Gynaikokratic der alten Meltnach i hrer religiosen and rechtlichen Natur. Brasilea, 1861, Madrid, 1992.; J.F. McLennan, Primitive Marriage, tempranamente por J.Rosembau hacia 1839 y Cantarella F., Según Natura. La bisexualidad en el mundo antiguo. Para estudios más recientes ver: ALFARO G. C., y NOGUERA B. A. (Eds.) Actas de Primer Seminario de Estudios sobre La Mujer en la Antigüedad. Universidad de Valencia, SEMA Ed., 1998. LOPEZ, A., MARTÍNEZ C., POCIÑA A. (eds) La mujer en el mundo Mediterráneo Antiguo. Universidad de Granada, Granada, 1990; DALTON, P. M., Mujeres Diosas y Musas. Tejedoras de la Memoria. El colegio de México, México, 1996.; DEL OLMO, L.G., La mujer en la Antigüedad. Barcelona, 1985. ZINSER P.J. y ANDERSON S. B., Historia de las Mujeres. Una historia Propia. Vol. I, Crítica Ed. Barcelona, 2000; DUBY, G. y PERROT M., Historia de las Mujeres en Occidente. La Antigüedad., Santillana, Madrid., 2000. POMEROY, S. Diosas, rameras, esposas y esclavas. Mujeres en la Antigüedad Clásica. Madrid, 1987. burdeles o eran prostitutas, algunas cortesanas ${ }^{2}$, también hechiceras y parteras. Las mujeres de la clase alta, aliviadas económicamente a través de la dote que les concedía su familia, buscaban el bienestar de su esposo y servían de enlace político y dinástico entre familias. Así lo hicieron las familias macedónicas, ptolemaicas y seleúdicas en el siglo IV al I a.C (ZINSER P.J. y ANDERSON, 85:2000). La mujer entonces se utilizó como objeto de intercambio, alianzas, disputas, conquistas y premios en los juegos de competitivos; se convirtió en botín de guerra, en productoras de bienestar y adquirió un valor de uso, considerada objeto de producción e intercambio.

La existencia jurídica de las mujeres era prácticamente nula y debían estar bajo dependencia masculina permaneciendo siempre en el interior de la casa. En Esparta y Creta podían poseer tierras bajo la condición que estar casadas y que la administración de sus bienes corriera a cargo de su marido o algún familiar masculino en el caso de que fuera soltera (PONCIÑA, 45:1990). En todo el territorio mediterráneo se excluía a las mujeres de las actividades fuera de la familia, con lo que los ámbitos asignados a los hombres: la guerra, el gobierno, la filosofía, la ciencia y la religión les estaban prohibidos. Excluida de los poderes públicos, la mujer se definía siempre en relación con su actividad sexual con el hombre. En este sentido, la virginidad y castidad estaban problemáticamente relacionadas con la obediencia y su cuerpo soportaba el peso del honor de toda una familia. La mujer ideal debía por lo tanto, ser sexualmente fiel a su esposo, ser fértil y criar hijos sanos, preferiblemente varones, dirigir la familia y cumplir con el papel de esposa, destinado a satisfacer las necesidades de los otros (ALFARO G. C., y NOGUERA B. A, 27:1998).

A las mujeres hebreas de la Edad Antigua, se les concebía dentro de un destino similar, imposibilitadas de rendir el culto hebreo, de leer la Torá y de practicarla dentro de las sinagogas ${ }^{3}$. La meta ansiada de toda mujer libre era el matrimonio y lo hacían casi siempre con hombres mayores que ellas. Las esposas judías llamaban a sus esposos "mi amo" y los hombres llamaban a sus esposas "mi hermana". Dentro del matrimonio, el hombre guiaba y cuidaba de la esposa, mientras ésta únicamente le daría hijos. Influenciados por la teología griega, la civilización romana comparte la misma situación

2 Mientras que las prostitutas eran despreciadas y diferenciadas del resto de las mujeres, una mujer atrevida y rebelde podía acceder a la función superior de cortesana. Famosas no sólo por sus servicios sexuales, sino también por sus habilidades sociales como acompañantes y consortes, las cortesanas se movían en los círculos más elevados. En la Atenas clásica, las cortesanas eran las únicas mujeres a las que se les permitía participar en las cenas y las reuniones que organizaba la élite masculina de la vida social griega. Platón alabó la inteligencia de Aspasia, la querida de Pericles, que fue considerada la mujer más famosa de la Atenas del siglo $\mathrm{V}$ a. C. CANTARELLA, Eva. La calamidad antigua: condición e imagen de la mujer en la antigüedad griega y romana. Traducción Pociña, Andrés. Ediciones Clásicas Madrid, 1996

3 Hacia el siglo I, los hombres judíos agradecían a Dios "que no me has hecho mujer". En la Mi?ná una colección de comentarios jurídicos, se señalaba que la menstruación hacía a la mujeres seres impuros dando una razón de su exclusión del templo. Graves R., y Patai R., Los Mitos Hebreos, Madrid, Alianza, 1986, p., 59. 
social para las mujeres (BOTINAS, 78: 1998). La innovación de los romanos sería la sistematización y la enseñanza del derecho con La creación de la "Ley de las Doce Tablas" o "Doce Tablas de la Antigua Roma" (Lex Duodecim Tabularum) redactada entre los años 451 y 450 a.C. ${ }^{4}$ El derecho, supuso la primera recopilación de las normas para las que deben regirse las relaciones de los ciudadanos reformulando las relaciones entre los sexos en todos los aspectos fundamentales: privados y públicos, familiares, laborales, etc., en ellos se incluye la primera codificación de la figura masculina y su comportamiento hacia las mujeres: concedía al padre poder para matar a su hija si lo consideraba apropiado, concedía únicamente el divorcio al hombre y beneficiaba básicamente a los varones de las familias que deseaban establecer nuevas alianzas políticas desposando a mujeres de sus aliados. (D'AMBRA 81:2007)

Que ésta subordinación y orden social, donde lo masculino rige lo femenino, fuera asumida por la totalidad de las mujeres no es una afirmación acertada y ante esto encontramos numerosos nombres de mujeres que se abrieron paso dentro de los templos, parlamentos políticos, imperios y revueltas armadas, destacando por su erudición, su capacidad para realizar alianzas o apoyar determinadas inversiones sociopolíticas ${ }^{5}$. Alrededor del siglo I, algunas mujeres desempeñaron el cargo de sacerdotisas-jueces, combinando el poder religioso y secular. ${ }^{6}$ No obstante, tanto las sacerdotisas como el resto de mujeres del pueblo, poseían como modelo de conducta los comportamientos y atributos de las diosas: la belleza, la virginidad, la obediencia, su gran capacidad fecundadora y maternal, confinadas siempre a un espacio privado

\section{Los textos de LA ANTIGUA Grecia}

Comencemos por analizar las fuentes que tenemos, centrándonos en localizar dentro de ellos a las figuras y personajes femeninos. De las fuentes literarias que se consideran las más antiguas, son quizás la Iliada, la Odisea y la Teogonía las obras que poseen los relatos más completos de los mitos griegos, narrando la creación del

4 A partir de Augusto la ciencia del derecho tuvo una gran importancia y hubo notables jurisconsultos, como Gayo, Ulpiano y Papiniano. Sus autores fueron 10 magistrados denominados decenviros, y se inscribio sobre tablas de bronce o madera que fueron colocadas en el principal foro romano. Llegó Occidente Tomo 1, La Antigüedad, Santilla, 1993, p. 34.

5 La mayoría de estas mujeres pertenecían a familias dinásticas que a favor de su familia, intentaron manipular el sistema de alianzas dinásticas. Las que lo hacían entraban en situaciones peligrosas y prohibidas, expuestas a los castigos y críticas más severas. Un ejemplo es Olimpia, madre de Alejandro Magno, Agripina II (15 -59 a.C.) emperatriz de Roma, La Historia de las Reinas Francas del siglo VI, Brunilda y Frenegunda, acusadas de embaucadoras de hombres, asesinas e incitadoras de guerras. CICOTTI, E., Donne e politica negli ultimi anni delle República Romana, Napoli Jovene, 1985.

6 La pitia de Delfos actuaba como oráculo del dios Apolo, las vírgenes vestales de Roma, Casandra quien rechazó el amor de Apolo y fue condenada a relatar autenticas profecías que nadie escuchaba. MONTERO, Santiago, Diosas y Adivinas. Mujer y adivinación en la Roma Antigua. Trotta, Madrid, 1994, p. 27. mundo y los orígenes de los dioses en una especie de génesis del orden del discurso del mundo antiguo 7 . Hesíodo, ofrece en su Teogonía el relato más completo de los primeros mitos griegos, tratando el origen de los dioses, los Titanes y los Gigantes, incluyendo elaboradas genealogías, relatos populares y mitos etiológicos. El poeta da consejo sobre la mejor forma de triunfar en un mundo peligroso vuelto aún más peligroso por sus dioses.

En lo que respecta a la épica de Homero, la mitología se centra en una estructura básica en donde un héroe se ve inmerso en numerosas empresas peligrosas o problemáticas para obtener el objeto deseado, que puede ser la búsqueda de una compañera, la mujer amada, la conquista de un reino o la búsqueda de la inmortalidad. En sucamino, es ayudado por elementos simbólicos quelepermitirán vencer las vicisitudes, dominando sobre todo 1 miedo. El héroe se ve le permitiran 作 por una for eseo lo lleva a poner en riesgo su propia vida. Ast el adquirir un objeto de deseo se coloca en una lógica de la voluntad, investido de predicados modales "pasionales" que oscilan entre el deseo y el desasosiego. (PELLIZER, 48:1985)

Lo "femenino" en la narrativa de ambos autores aparece normalmente presente desde el momento "primordial", emparejado con el elemento "masculino", indispensable como éste para poner en marcha el proceso procreador. En éste sentido, su función simbólica corresponde a la de la Gran Diosa Madre (de los dioses). La función primordial de esta diosa-madre (de los dioses) es el de la génesis del cosmos, con una figura procreadora, protectora, circunscrita al ámbito del hogar, el del padre o del esposo o del hermano-esposo. ${ }^{8}$ Las diosas cuando viajan lo hacen casi siempre en compañía masculina, se relaciona con los pueblos a través de sus huéspedes y puede ser codiciada por otros dioses. Sus pecados son caseros, incluso cuando comete asesinato lo hace contra alguna divinidad, familiar o huésped. Rescatan de la muerte a sus esposos o hermanas, descienden a los infiernos para servir de sustitutos a sus amantes y dar continuidad al ciclo de la vida, son las grandes tentaciones a vencer por los profetas, Dharmas, hombres y personajes mitológicos.

La figura de la diosa, aun siendo un ser supremo, no abandona el espacio de lo privado incluso, ella misma conforma el espacio privado: Gea, en la Teogonía es nombrada como "la casa siempre sólida de todos los inmortales"

7 La antigüedad de su aparición no impide nombrar otros textos de corte religioso que les influyeron en gran medida: el Pentateuco de los hebreos (escrito entre c.1150 y c. 250 a.C., conocidos como los cinco primeros libros del Antiguo Testamento de la Biblia); los Vedas Hindúes, en los tiempo de Buda (VI a.C.); Epopeya de Gilgamesh, una narración de origen sumerio, considerada como la narración escrita más antigua de la historia; la literatura Egipcia del Imperio Antiguo, (tercer milenio a. C. ) y la mitología persa (650 a.C.). Comte F., Los libros sagrados. Alianza, 1995, Pp. 20 - 169.

8 En la Mitología Griega, las diosas Gea, Artemisa, Deméter, Afrodita,Hestia, Hera representan a la fertilidad y exaltan la virginidad; la admirada Penélope de Homero, es valorada por el autor por su fidelidad a Ulises y la sumisión que demuestra a su hijo.

9 WEST, M. L., Hesiod Theogony, Oxford, 1996, p. 23. 
o diosas contenidas en ambos textos y en general, en la totalidad de la producción literaria de la Edad Antigua, son irrelevantes, en tanto que sirven para expresar la esencia de la eticidad, una sustancia ética fijada por un destino irremediable a un signo mujer que, como dice Celia Amorós "carece de identidad en la medida en que no es representación del "Género". Como todo signo e imagen de mujer, las diosas y personajes femeninos de los autores parecen encarnar al género; o mejor dicho, el sentido fijado a esta imagen arquetípica, el cual no es independiente del género que representa. De poco sirve a la o el lector o lectora feminista esta segregación de sujetos y signos de mujer si se continúa con la adhesión a los valores simbólicos delos mundos representados y a los sentidos sexistas fijados. En palabras de Lola Luna "atención al mero análisis descriptivo de la imagen de la mujer sin una perspectiva crítica feminista, porque podemos perpetuar unas relaciones entre géneros que han sustentado históricamente en un sistema de subordinación de la mujer". Centraremos pues la lectura y el análisis desde la perspectiva de género, sobre aquéllos personajes "femeninos" contenidos en la Iliada, la Odisea y la Teogonía, que subvierten el estereotipo destinado para una mujer dentro del orden del discurso patriarcal en el mundo antiguo, en el cual evidentemente, desarrollaban su vida ambos autores.

\section{LA NOCHE COMO ORIGEN DE LA SUBVERSIÓN}

En Teogonía, Hesíodo expone el origen del mundo a través de sus genealogías, así en el comienzo de los tiempos, Caos da origen a Gea y a la Negra Nix (Noche). Sabemos que la noche es una figura femenina toda vez que da a luz a Éter y Día ${ }^{10}$. La residencia de Noche, se sitúa al otro lado del Océano, donde se aguardan las temibles Górgonas, las Herpérides, y Medusa. Nix concibe dos tipos de retoños: los que concibe sola y los que pare con Erebo:

"La Noche concibe, sin unirse a ningún Dios a una serie de "muchedumbre" de los sueños Tánatos, Hipnos, Moiras, Keres, Clotos, Lacesis y Atropos" (Teogonía, $125-128)$

Es madre de seres terribles como Némesis, Apate, Eris cuyo hijo es Algos (por quien se llora, y señor de las batallas) e Ismina (exterminio de los guerreros, palabras engañosas o menosprecio de las leyes). Polémicas son sus hijas Moiras y las Keres que conceden el bien y el mal a los hombres, así como Momo (lamento o sarcasmo), Eris y su estirpe:

La funesta noche... engendró a la astuta Eris... quien parió a la dolorosa Fatiga, al Olvido, al Hambre y los Dolores que causan llanto, a los Combates, Guerras, Matanzas, Masacres, Odios, Mentiras... al Desorden y a la Destrucción, compañeros

10 Contrariamente con la estirpe de Zeus en el periodo olímpico, las diosas Atenea, Afrodita, Artemisa, Hestia son representadas como la sabiduría, el valor, la belleza, la virginidad y la fertilidad. BERNARDO, G. DI, La insuurrección de Lilith Arcibel, 2009, Pp., 52-62. inseparables y al Juramento el que más dolores proporciona a los hombres. (Teogonía, 224-233.)

También Noche es madre del contacto amoroso porque se practica durante la noche; que la noche y el día estén sexuados adquiere preponderancia para la figura femenina, toda vez que Noche es sexuada como femenina, representándola como la oscuridad, lo desconocido, lo invisible, el mundo de la inseguridad y la muerte (POMEROY, 49:1987). Las hijas de la Madre Noche, hijas de una madre que subvierte el orden patriarcal del cosmos, sintetizan en su actuación el lado oscuro de lo impredecible, la maldad, el destino siniestroalquesedebetemerysonconsideradasporHesíodoactitudesocomportamientos femeninos, (DALTON, 170:1996) creadoras de desgracias para los seres humanos. En la diosa Nix preolímpica existe un poder que se pierde bajo el reino de Zeus, porque con él hay una reagrupación de los poderes. Para Guthrie, Hesíodo y Homero son los que otorgan una relevancia a Zeus como dios esencial que anteriormente no poseía toda vez que era un dios menor en el tiempo de la guerra de Troya ${ }^{11}$.

Las hijas subversoras, se constituyen como sistema simbólico del mal o del miedo en el imaginario de la Antigua Grecia. Ricoeur ${ }^{12}$ sostiene que hay un lenguaje originario y elemental que es el que subyace en la mítica y que es ahí donde reside la simbólica del mal, es decir las nociones primarias de maldad, culpabilidad, pecado, que conforman la experiencia vivida del mal. Siguiendo al autor, estas nociones son símbolos a través de los cuales es posible reproducir la experiencia que expresan y a su vez, esta experiencia es la que funciona en el relato mítico y en la especulación. La experiencia del mal representada en la subversión o mejor dicho lo femenino como insurrecto, no se limitó a significar, si no que, activó la maldad misma en la experiencia cotidiana.

Las figuras femeninas subversivas en la mitología Hesiódica y Homérica aparecen en menor frecuencia que el resto, son evocadas en la historia como capaces de hacer fallar al héroe en su persecución del objeto deseado, infundiéndole temor, duda o desesperanza y parece haber una clara tendencia en los autores en sistematizar a las figuras femeninas insurrectas en el ámbito de una sola familia: una raza de figuras deformes, híbridas, que infunden temor y angustia. La mayoría asumen denominaciones simbólicas con rasgos bestiales o sufren metamorfosis con animales, produciendo una serie de híbridos femeninos monstruosos y caóticos (PELLIZER,

11 Ya en la etapa olímpica de Zeus, las deidades se integran al discurso simbólico de un orden "masculino", donde el padre domina y controla el cosmos. Esto podríamos compararlo a la aparición en Egipto de las culturas monoteísta y la desaparición de las divinidades femeninas. Gutherie W.K.C., Orpheus and Greek Religion Graphic Society, New York, 1963 p. 61.

12 Esta interpretación de los símbolos primarios no debe hacernos olvidar su simultaneidad de sentido en la totalidad que constituye toda la Simbólica. Lo originario no es nunca punto de partida sino el punto de llegada de la reflexión. La noción del texto requiere, ser ampliada más allá de los límites del mero discurso escrito. SAN JOSÉ, A. J. E., El mal en la filosofía de la voluntad de Paul Ricoeur, Pamplona EUNSA, 2008

Revista Internacional de Culturas y Literaturas, abril 2009 
56:1985). Padre toda esta estirpe terrorífica es Hesíodo, quien señala que de la unión de Porkhos y Cetó, surgen una serie de criaturas monstruosas y feroces entre ellas las tres Gorgonas -cuya líder es Medusa- Scilla, Hidra, Esfinge, Sirenas, Hécate, Harpíasy toda una serie de entelequias que sistemáticamente conforman el universo del "miedo" y que habitan en la morada de su madre la Noche, al otro lado del Océano (Teogonía, 245267). Estas representaciones figurativas perversas, no tienen una forma precisa, una morfología interpretable, son figuras inestables o difícilmente imaginables: Esfinge, una criatura con busto de mujer, cuerpo de leona y alas; las sirenas, cuerpo de pez y busto humano; Medusa, con serpientes por cabellos, la misma Hécate imaginada con tres cuerpos o cabezas que son a la vez viejas y jóvenes, las Górgonas, mujeres con alas y serpientes por cabellos. Son manifestaciones aparentemente ambiguas y contradictorias que confirman una oposición entre deseo/angustia y aparecen en la narrativa épica como figuras que obstaculizan la consecución del objeto del deseo en la estructura básica del relato (GARCÍA, 140:1987).

Notaremos que aquéllas diosas, divinidades o hechiceras que aparecen dentro de la historia y protagonizan un enfrentamiento con el héroe o rupturas con el orden establecido dentro de la narración ${ }^{13}$, son nombradas y representadas como seres perversos, malévolos y peligrosos que nacen en el lado oscuro del mundo, específicamente en el vasto árbol genealógico de las y los hijos de la Noche. Lo mismo ocurría con aquéllas mujeres de la edad antigua que subvirtieron el orden social de su época, encontrando destinos funestos para ellas y sus familias. Dichas mujeres pasaron a la historia erróneamente nombradas, simbólicamente representadas con valores peyorativos, mismos que han sido retomados y sustentados por la mayoría de los textos sagrados o fundacionales de las culturas alrededor del mundo.Realizar una crítica feminista en la interpretación de dichos textos es adentrarse en el cuestionamiento de buena parte de lo que existe en el mundo como lo "verdadero" y lo establecido. Es una manera de subvertir las lecturas y modos de lecturas que nos han configurado como lectores y que nos han transmitido simultáneamente modelos de identidad sexual mediante roles o estereotipos sociales, arquetipos y mitos. Para el caso de nosotras las y los lectores feministas, en el momento en que diferimos del sentido fijado en los textos y tenemos otra visión, estamos siendo rebeldes, subversivos. Estamos sin duda, desmitificando aquéllas figuras olvidadas por la historia y que lamentablemente tiene rostro de mujer. La crítica feminista aquí presentada desea ser parte de ése nuevo lenguaje que se resistente a los estereotipos con los que se construye el sistema de definiciones de lo

13 En la Odisea, Circe atrae a los hombres de Odiseo para hacerlos prisioneros y retiene así al Héroe en el retorno a Itaca. Calipso retiene a Ulises en la Iliada, Helena, es la causa de la guerra entre Troya. Pandora dotada de voz, abre su caja con la que desata todos los males de la humanidad, Medusa enamoraría a Neptuno, quien posteriormente tendría que sacrificarla enviando a Perseo. GARCÍA, Sánchez M., Las mujeres de Homero, SEMA, 1999, Universitat de Valencia, Pp., 23-80.

$$
\text { Revista Internacional de Culturas y Literaturas, abril } 2009
$$

femenino como "inferior" esperando que su visión sea retomada por otras y otros lectores que deseen contribuir a la creación de un mundo igualitario.

REFERENCIAS BIBLIOGRÁFICAS

Alfaro G. C., y Noguera B. A. (Eds.), Actas del Primer Seminario de Estudios sobre La Mujer en la Antigüedad, SEMA Ed., Universidad de Valencia, 1998.

Anderson S. B. y Zinser, P. J., Historia de las Mujeres: Una historia propia Vol. I., Crítica, Barcelona, 2000

Bernardo, F. G., La insurrección de Lilith, Arcibel Editores, Sevilla, 2009.

Bermejo, J. C., Los orígenes de la Mitología Griega. Akal Editores, 1996.

Botinas Montero, E., "Sobre un simbólico divino femenino"en De los Símbolos al orden simbólico femenino (Siglos IV-XVIII) Al-Mudayana, 1998.

Butler, J., El Género en Disputa. El feminismo y la subversión de la identidad. Paidós, 2007.

Cantarella, E., La calamidad antigua: condición e imagen de la mujer en la antigüedad griega y romana, Ediciones Clásicas, Madrid, 1996.

Cicotti, E., Donne e politica negli ultimi anni delle República Romana, Napoli Jovene, 1985. Comte, F., Los Libros Sagrados, Alianza Editorial, 1995.

Dalton Palomo, M., Mujeres Diosas y Musas. Tejedoras de la Memoria. El Colegio de México, México, 1996.

D'Ambra, E., Roman Women, Cambridge, University Press, 2007.

Duby G. y Perrot M., Historia de las Mujeres en Occidente. Tomo 1, La Antigüedad, Santilla, 1993.

García Gual, C., La mitología. Interpretaciones del pensamiento Crítico, Montesinos, 1987. García Sánchez M., Las mujeres de Homero, Universitat de Valencia, SEMA, 1999.

Graves, R. y Patai, R., Los Mitos Hebreos, Alianza, Madrid, 1986.

Gutherie,W.K.C, Orpheus and Greek Religion, Graphic Society, New York, 1963.

Homero, Odisea Versión y Prólogo de Carlos García Gual, Alianza Editorial, Madrid, 2004.

Hesíodo, Teogonía Traducción de Luis Segala y Estalella, Teorema, Barcelona, 1986 J.F.M. N., Diccionario de Mitología Universal Tomo I y II, Edicomunicación, España, 2003.

Lerner, G., La creación del patriarcado, Crítica, Barcelona, 1990.

Lete Del Olmo, G., La donna nell'antichità, Universidad Internacional Menéndez y Pelayo. Seminari: Deesses i Hiroines en les Mitologies e antigues, Editorial AUSA, Barcelona, 1985 
López, A., Martínez C., Pociña, A. (eds), La mujer en el mundo Mediterráneo Antiguo, Universidad de Granada, Granada, 1990.

Martín Sánchez, A. y M, Á, Hesíodo, Teogonía y Los Trabajos y los días, Alianza, Madrid,1986.

Martínez Nieto, R. B., La aurora en el pensamiento griego: las cosmogonías prefilosóficas de Hesiodo, Alcman, Ferecidas, Epiménidas, Museo y la Teogonía órfica antigua. Trotta, Madrid, 2000.

Merssini, F., El Harén político. El profeta y las mujeres, Ediciones de Oriente y del Mediterráneo, Madrid, 2002.

Montero, S., Diosas y Adivinas. Mujer y adivinación en la Roma Antigua, Trotta, Madrid, 1994.

Muraro, L., El orden simbólico de la madre, Horas y horas, Madrid ,1995.

Pomeroy, S., Diosas, rameras, esposas y esclavas. Mujeres en la Antigüedad Clásica. Madrid, 1987.

Rivera Garretas, M., La historia de las Mujeres, ¿es, hoy, la historia? en La Historia de las mujeres en el nuevo paradigma de la Historia. Ed. Cristina Segura, Al-Mudayana, Madrid,1997.

Saenz Alonso, M., "Hécate, Muerte, Noche, Mujer" en Congreso de San Sebastián Brujología.

San José Albertos, Jesús, El mal en la filosofía de la voluntad de Paul Ricoeur EUNSA, Pamplona, 2008.

Strathern, M., Women in between: female roles in a male world, Mount Hagen, New Guinea, London Seminar Press, 1972 .

Tremosa, L. y Calvet i Puig, D., "Las olvidadas de la historia", en Mujer y ciudadanía. Bellaterra, Barcelona, 2001.

West, M. L., Hesiod, Theogony Oxford, 1996. 